\title{
Long-distance Liquid Coarticulation in American English
}

\author{
Nancy Hall ${ }^{1}$, Nancy Vasquez ${ }^{1}$, Francisco Aguirre ${ }^{1}$, Muhammad Damanhuri ${ }^{1}$, and \\ Connor Tree ${ }^{2}$
}

California State University Long Beach ${ }^{1}$, Mira Costa High School ${ }^{2}$

\section{Introduction}

1.1 Long-range liquid coarticulation in British dialects In British English, the liquids /l/ and/or /r/ can trigger coarticulation spanning several syllables in either direction. Typically, British dialects have one 'clear' liquid, with a relatively high F2, and one 'dark' liquid, with low F2. Dialects differ as to which of /// and $/ \mathrm{r}$ / is clear and which is dark. Kelly \& Local (1986) showed that in several dialects, the F2 values associated with the liquids affected vowels not adjacent to the liquid: for example, in the sentences Let Terry/Telly do it, the F2 difference associated with the $1 / \mathrm{r}$ distinction was realized in vowels throughout the underlined portion of the sentence.

Subsequent studies replicated and extended this finding. Tunley (1999) found that, compared to a neutral /h/ phoneme, /r/ lowers the F2 and F3 of unstressed vowels for two syllables on either side in Standard Southern British. West (1999a) and West (2000) examined the articulatory realization of long-range effects: using electromagnetic articulography and electropalatography, she found more lip rounding and a higher, more back tongue position at least two syllables before /r/ as compared to /l/, in Standard Southern British. Although most studies only examined a window of two syllables per side, Heid \& Hawkins (2000) found effects over even longer domains. Inserting words into eight frame sentences that systematically varied in segmental content and stress pattern (We 'heard it (')might/could be (a)____ ), they found that anticipatory effects stretched to the word it, which was four or five syllables before the liquid depending on whether the liquid was in the first or second syllable of the target word. Interestingly, the r/l context did not reliably affect the words might/could, even though these words intervened between it and the liquid. This suggests that anticipatory effects can pass through segments that do not participate in them. Heid \& Hawkins conclude that liquids have two coarticulatory effects: one that is large, short-range, and interacts with segmental context, and another that is small, long-range, and less influenced by segmental context.

Examples of the extent of liquid coarticulation in British are shown in (1).
Let Terry/Telly do it
Kelly \& Local (1986)
Have you uttered a leap/reap at home?
West (1999a)
We heard that it might be a berry/belly.
Heid \& Hawkins (2000)

The cause or function of long-range coarticulation is somewhat unclear. As Heid \& Hawkins (2000) note, "it seems to give /r/ and /l/ an importance that they do not seem to have in lexical decision-making." Nevertheless, West (1999b) found that listeners do exploit long-range coarticulation to identify liquids. When a liquid and its adjacent vowels were replaced with white noise, participants were able to identify the liquid with better than chance accuracy in a forced choice task. They must have detected the acoustic effects on non-adjacent vowels and recognized them as stemming from liquid coarticulation. Similarly, Heinrich \& Hawkins (2010) find that long-range coarticulatory effects improve the perception of speech heard in noise.

\footnotetext{
${ }^{1}$ This research was supported by the National Institute of General Medical Sciences of the National Institutes of Health under Award Numbers 5UL1GM118979-03; 5TL4GM118980-03; 5RL5GM11897803 . The content is solely the responsibility of the authors and does not necessarily represent the official views of the National Institutes of Health.
} 
Tunley (1999), as well as Hawkins \& Slater (1994), find that adding coarticulatory detail to synthetic speech improves the perception of liquids.

Although long-range coarticulatory effects are generally attributed to both liquids, some of the British studies have compared only /l/ and /r/, without a baseline of a non-liquid consonant. This makes it unclear whether long-range effects are equally robust for $/ \mathrm{l} /$ and $/ \mathrm{r} /$ (since long-range differences between the two could result from only one having coarticulatory effects).

1.2 Long-range coarticulation in North American English There has been relatively little study of long-range liquid coarticulation in North American dialects. Because these dialects have liquids with different phonological and phonetic characteristics than British dialects, they offer the opportunity to examine possible factors affecting long-range coarticulation that have not previously been considered.

For example, most British dialects are non-rhotic, meaning that $/ \mathrm{r} /$ occurs only prevocalically, in syllable onset position. Most North American speakers, however, also have /r/ in syllable nuclei (where it is realized as [ə]) and in codas. Some speakers also have a syllabic $/ \mathrm{l} /$, in words like pull, usually as a variant of $/ \mathrm{vl} /$ or /əl/. This wider phonological distribution of liquids means there is also potentially a greater range of phonetic realizations for liquids within the same dialect. Liquids may have different local phonetic properties depending on their position in the syllable; for example, some Americans have a "clear" / $1 /$ in onset position and a "dark" /l/ in coda position, and the opposite pattern for /r/ (Olive et al. 1993:204, 216). This variation raises the possibility that /l/ or /r/ might have inconsistent long-range effects depending on their syllable positions. Alternatively, it is possible that greater variability in liquid articulations reduces the perceptual utility of long-range coarticulation, since for some speakers, F2 lowering might be associated with one liquid in onset position and the other in coda position. If onset, syllabic and coda liquids should prove to have different patterns of long-range coarticulation, this could add to our understanding of the factors that cause such coarticulation.

To our knowledge, only Kochetov \& Neufeld (2013) have found evidence of long-range liquid coarticulation in North American English. In their study, fifteen speakers of Canadian English repeated each of the sentences we thought it might be a ram/ham/lamb/dam 30-45 times. Analysis of formants found limited long-range effects: in it and thought, F3 was significantly lower before /r/ than before /h/. There were no significant F2 differences, presumably because Canadian /l/ and /r/ have relatively similar F2 values (unlike British dialects, where typically one liquid is dark and the other light). The F3 finding replicates Heid \& Hawkin's finding that coarticulation can spread as much as four syllables, and that stressed might neither participates in nor blocks the coarticulation. A second analysis method, based on long-term average spectra (LTAS), found more robust long-range effects, but they are primarily differences between coronals and noncoronal $/ \mathrm{h} /$ rather than differences within the coronal class.

A study in our own lab (Maloney et al. 2016) failed to find significant long-distance effects in California speech. A speaker read 252 repetitions of It sounded as if it said __ about then, with word pairs that contrasted /r/ and /l/ in varying positions, such as bar / ball and read / lead. The immediately adjacent word said showed local coarticulatory effects, as expected. The preceding four syllables ( $e d$ as if it) all had trends towards lower F2 and lower F3 before /r/, reaching near-significance for the word if ( $\mathrm{p}=.054$ for F2, $\mathrm{p}=$ .076 for F3), but none significant. Following syllables were not analyzed. This study had fewer datapoints than Heid \& Hawkins (2000) or Kochetov \& Neufeld (2013), so it is possible that the lack of significant findings reflects low power. However, West (1999a) and West (2000) achieved significant results with relatively few tokens.

The results of Kochetov \& Neufeld (2013) and Maloney et al. (2016) both suggest that long-range liquid effects might be weaker in North American English than in British.

1.3 Implications for phonology Clarifying the extent and nature of liquid coarticulation is relevant to a long-standing debate in phonology: the cause of the process of long-range dissimilation. In many languages, the presence of identical liquids within a word is avoided by deleting or changing one of them, as in Latin /lun-alis/ $\rightarrow$ [lunaris] 'lunar'. American English has an optional, sporadic process of long-range $/ \mathrm{r} /$-dissimilation, which usually takes the form of [ə] dissimilating to [ə] in words containing another rhotic. Although the rhotics are often in adjacent syllables, as in surprise (sə-pıaız səpıaız) they can also be separated by one or more syllables. Examples in which the dissimilation takes place over an intervening 


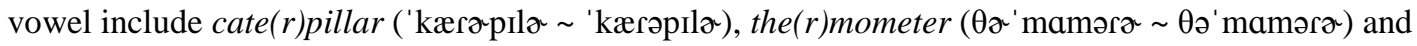
pa(r)ticular (pə'ttkjələ pə'trkjələ). In non-rhotic British dialects, of course, this dissimilation does not happen because these words do not contain $/ \mathrm{r} / \mathrm{s}$.

Ohala (1981) claims that dissimilation is caused by perceptual errors, when the long-range coarticulatory effects of one sound mask the presence of a similar sound elsewhere in the word. Suppose a listener hears [ə] at the end of caterpillar, and knows that this rhotic tends to cause (hypothetically) lowering of F3 throughout the word. This may cause the listener to interpret the low F3 in the second syllable as a longrange rhotic coarticulation effect superimposed on an underlying [ə]. If the listener perceptually over-corrects for the expected coarticulation, s/he may identify [ə] where [ə] was intended, resulting in an accidental dissimilation.

This approach to explaining dissimilation is controversial, in part because it breaks with the common assumption in phonology that sound changes occur in order to avoid sound structures that are marked. In most analyses, dissimilation is triggered by constraints against multiple identical segments within a given domain (e.g. Stanton 2016, this volume). Yet according to Ohala (1981), there are no rules or constraints dispreferring such structures; they disappear only if their phonetic implementation gives rise to perceptual ambiguities.

Hall (2007) argues that the patterning of American /r/-dissimilation is consistent with Ohala's theory. She notes that there is a difference in the means that speakers use to avoid multiple $/ \mathrm{r} / \mathrm{s}$ in close proximity versus multiple $/ \mathrm{r} / \mathrm{s}$ at a distance. Some of the methods used to avoid $/ \mathrm{r} / \mathrm{s}$ in close proximity clearly reflect deliberate choices. These include morphological strategies such as choosing analytic rather than affixal comparative forms for adjectives ending in / $\mathrm{r}$ (more bare instead of barer, Mondorf 1993), and even the avoidance of baby names containing close-together liquids (Martin 2007). Hall argues that such deliberate strategies are not used to avoid liquids at greater distance, which supports Ohala's assumption that such sequences are not dispreferred by the phonology. Furthermore, dissimilation tends to happen in the circumstances where perceptual mistakes are most likely, such as in unstressed syllables. She suggests that the perceptual ambiguity caused by long-range coarticulation also occasionally results in long-range liquid assimilation: speakers sometimes add an extra $/ \mathrm{r} /$ to words already containing one $/ \mathrm{r} /$, such as familiar

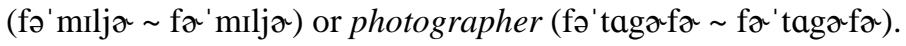

However, empirical evidence for the perceptual theory of dissimilation is lacking. In the only attempt we are aware of to produce perceptual dissimilation in the laboratory, Abrego-Collier (2013) found that listeners did not hypercorrect for liquid coarticulation. When presented with words containing liquids synthesized on an /r/-/l/ continuum, they tended to perceptually assimilate them to nearby liquids, perceiving an ambiguous segment as more $/ \mathrm{l} /$-like if there was another $/ \mathrm{l} /$ in the word. This is the opposite of Ohala's prediction.

In short, the perceptual explanation for liquid dissimilation remains debatable. A better understanding of liquid coarticulation is an essential step in resolving this question.

\section{Questions}

In this study, we attempt to answer the following questions:

1. Does a California speaker produce long-distance coarticulatory effects of $/ / /$ and $/ r /$ ?

2. Does the range / nature of any long-range effects depend on the position of the liquid within the syllable (onset, syllabic, or coda)?

3. Does the range / nature of any long-range effects depend on whether the liquid is stressed?

\section{Methods}

All methods were approved by the Internal Review Board of California State University Long Beach (project 814747-2). 
3.1 Materials Items consisted of 125 sets (pairs or triplets) of real English words containing $/ \mathrm{l} / \mathrm{,} / \mathrm{r} / \mathrm{or}$ neither. The 'neither' condition might have Ø (no consonant) in the position corresponding to the liquid (for example, pray / play / pay), or a non-liquid consonant such as [h] or [t] (tall / tar / tot).

Where possible, the sets formed minimal pairs or triplets. However, the limitations of the English lexicon often precluded this, particularly in the case of unstressed liquids which necessarily occur in multisyllabic words. Since the goal was to measure anticipatory coarticulation, differences within sets were limited to segmental material following the liquid.

Word sets fell into seven groups based on stress and liquid position, as described below:

\section{Word Groups}

Stressed simple onsets: 12 minimal triplets of monosyllables contrasting / $/ \mathrm{l} /, / \mathrm{l} /$ and $/ \mathrm{h} /$.

Unstressed simple onsets: 10 triplets contrasting initial /.د/ and /lə/, followed by a stressed syllable. Due to the rarity of such words, most of the /.ı/ and /la/ items are not minimal pairs, but they are controlled to have similar onsets and vowels in the stressed second syllable (e.g. redeem, Latino: rə' dim, lə'tino). The word in the 'neither' condition is missing the unstressed first syllable; it begins with a stressed syllable whose onset and vowel are similar to those of the stressed syllables following the liquids (e.g. team completes the pair above). The goal was to equalize any long-range effects of the stressed vowels and/or their onsets.

Stressed complex onsets: 24 minimal or near-minimal triplets contrasting /I/, /l/ and $\varnothing$ following initial consonants; 12 of them with velar consonants and 12 with labial. All but one set are monosyllabic. Triplets are controlled for vowel, but a few vary final consonant.

Unstressed complex onsets: 12 pairs contrasting initial consonant clusters with //I/ and /l/. 6 of the preceding consonants are velar and 6 labial. Due to the rarity of such words, none are minimal pairs, but are chosen to have as many similarities in the liquids' segmental context as possible. For the same reason, no condition without liquids was included.

Stressed syllabic: 18 minimal or near-minimal triplets contrasting / $/, / 1 /$ and $/ \curvearrowright /$ in stressed initial syllables. ${ }^{2}$ The preceding consonant is controlled, with 12 labials, 2 coronals, and 4 velars. Words that can be pronounced with [1] generally have variant pronunciations with [əl] or [əl]; 7 words where the speaker produced these variants were excluded.

Unstressed syllabic: 22 pairs contrasting / $/$ with /ə/ or Ø. Word Sets are controlled for preceding consonant (12 labial, 2 coronal, 8 velar). Due to the rarity of such words, word ends often vary. It was not possible to find enough items with unstressed /1//, so this condition is excluded from this set.

Stressed coda: 27 minimal or near-minimal pairs contrasting /x/, /l/, and either $\varnothing$ or a non-liquid coronal. The preceding consonant and vowel are controlled, with 12 labials, 12 coronals, and 3 velars.

Table 1 summarizes the seven groups with sample sets.

\begin{tabular}{|c|c|c|c|c|}
\hline & Simple Onset & Complex Onset & Syllabic & Coda \\
\hline +Stress & $\begin{array}{l}\text { lock rock hock } \\
\text { lak tak hak }\end{array}$ & $\begin{array}{l}\text { blah bra bot } \\
\text { bla b.a bat }\end{array}$ & $\begin{array}{l}\text { pull purr putt } \\
\text { po pl pət }\end{array}$ & $\begin{array}{l}\text { tall tar tot } \\
\text { tal tai tat }\end{array}$ \\
\hline -Stress & $\begin{array}{l}\text { lagoon ragu goo } \\
\text { lə'gun .əə'gu 'gu }\end{array}$ & $\begin{array}{l}\text { placebo proceedings --- } \\
\text { pla'sibo pıə' sidinz }\end{array}$ & $\begin{array}{l}\text {--- Burkina bikini } \\
\text { bə'kinə bə'kini } \\
\text {--- burrito beet } \\
\text { bairo bit }\end{array}$ & --- --- --- \\
\hline
\end{tabular}

Table 1: Sample items by group

\footnotetext{
${ }^{2}$ In common with many young Californians, our speaker considers the vowel in putt to be the stressed equivalent of the unstressed vowels in $\underline{a}$ bout or sofa $\underline{a}$, and produces it in a relatively centralized position. For this reason, we transcribe it as [ə] rather than $[\Lambda]$.
} 
It should be noted that many factors inherently cannot be controlled across the seven stress/position conditions. Some groups have different stress patterns and syllable counts, which may affect prosodic features such as syllable length elsewhere in the phrase, which in turn can affect formant values. In addition, the seven conditions are not controlled for segmental content aside from the liquids, although we attempted to include a variety of stressed vowels and onset consonant types within each group.

Note also that / $\mathrm{r} /$ is included in all groups, but one group lacks /l/ (unstressed syllabic), and one group lacks the 'neither' condition (unstressed complex onset).

3.2 Participant The speaker (fifth author) is a male native English speaker from Southern California in his late teens, with no hearing or speech impairments. At the time of recording he was unaware of the purpose of the experiment.

3.3 Procedure The participant was recorded in a sound-dampening booth, using a PMD 660 solid state recorder and a Shure SM-35 head-mounted microphone. Target words were read in the frame sentence $\mathrm{He}$ said it 'oughta be_. The words were presented in pairs or triplets, in order to focus the participant's attention on the liquid contrasts. Pairs or triplets from different groups (such as stressed syllabic, unstressed onset, etc.) were mixed to avoid order effects.

The participant read the list four times, but as the first repetition had inconsistent sentence prosody, only the last three repetitions were analyzed.

Spectral analysis was conducted using Praat (Boersma \& Weenink, 2016). Fave-Align (Rosenfelder et al., 2011) was used for initial segmentation, which was then manually checked and adjusted as needed. Formant values at vowel midpoints were measured automatically using Praat's To Formant (burg) function. Outlying readings were manually checked and corrected if appropriate.

As noted above, some intended tokens of stressed syllabic / $1 /$ were judged (based on auditory impressions as well as examination of spectrograms) to be produced as $/ \mathrm{vl} /$ or $/ \mathrm{al} /$. Seven items were excluded for this reason.

After exclusion of these items, as well as of a few tokens whose formants could not be measured confidently, there remained between 984 to 994 tokens of each frame sentence word, reflecting up to three repetitions of 334 items.

\section{Results}

4.1 Local differences in liquids Since long-range liquid coarticulation is expected to reflect the same direction of formant differences as found locally between liquids, we first examine the liquids themselves. Figure 1 illustrates the speaker's production of /r/ and /l/ in each syllable position. Praat's tracking function was used to measure 5 timepoints within each liquid. In all positions, /r/ has higher F1 and F2, and lower F3, than /l/. The F2 differences between /r/ and /l/ are not dramatic, suggesting that unlike many British speakers (but similar to Kochetov \& Neufeld 2013's Canadian speakers), this speaker does not primarily distinguish the liquids as clear and dark. The sloping F2 contour of /1// suggests that some of the tokens may not be fully syllabic, but start as a more back vowel.

For all formants in all positions, differences between $/ \mathrm{r} /$ and $/ \mathrm{l} /$ at the segment midpoint are highly significant. We expect that long-range formant differences, if any, would be in the same directions. 

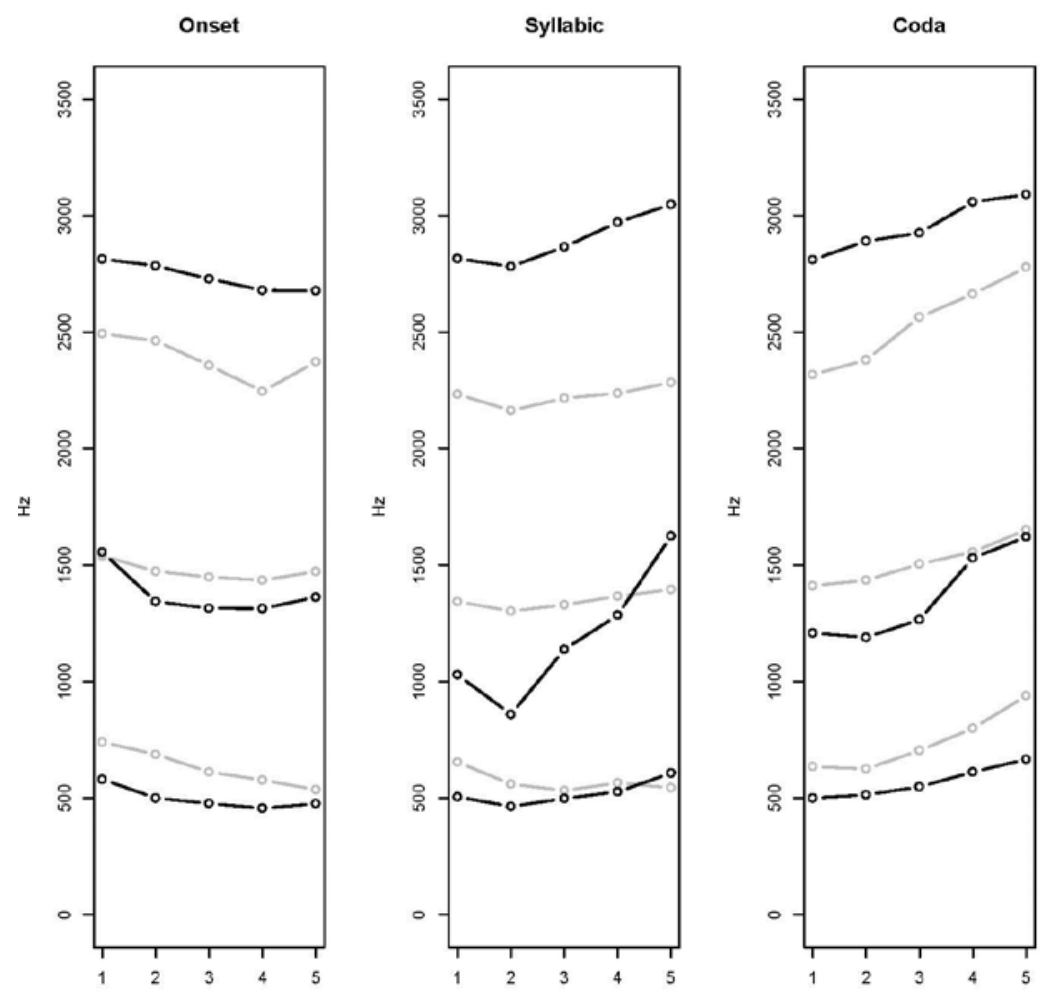

Grey $=/ \mathrm{r} / \quad$ Black $=/ \mathrm{l} /$

Figure 1: formant patterns by liquid and position.

4.2 Anticipatory coarticulation To examine the extent of anticipatory coarticulation, a series of paired t-tests were performed on F1, F2 and F3 of each non-adjacent frame sentence vowel. Tokens were paired within their word sets by repetition (so that, for example, the first repetition of the pull sentence was compared to the first repetition of the purr sentence). For each formant for each vowel, 3 comparisons were performed: /r/ versus /l/, /r/ vs no liquid, and /l/ vs no liquid. Results are summarized in Table 2. Note that since some sets contained only two members, the three pairwise comparisons do not involve the same number of tokens. This is why, for example, the average value of a formant in the null condition can vary depending on whether it is being compared to $/ \mathrm{r} /$ or $/ \mathrm{l} /$.

Five comparisons have p-levels below .05. If we apply a Bonferroni correction to maintain an overall alpha level of .05, only one of these comparisons remains significant: lower F1 for /l/ than r/ in said, which is five syllables before the liquids. Another effect, lower F1 for /l/ than no liquid in ta, is near significant.

Although the three effects involving ought do not reach significance after Bonferroni correction, it is worth noting that they are all in the direction of lower F1 and/or F2 before words containing liquids. Any involvement of stressed ought in coarticulation would be surprising, as Heid \& Hawkins (2001) and Kochetov \& Neufeld (2013) both found that stressed vowels do not participate.

The five effects are all very small in magnitude. Mean F1 differences are in the range of 7-15 Hz; mean F2 differences, 10-12 Hz. Kewley-Port \& Watson (1994) find the just-noticeable difference threshold for English vowels to be around $14 \mathrm{~Hz}$ in the F1 frequency region (below $800 \mathrm{~Hz}$ ), increasing in the F2 region. Thus, it is highly unlikely that any of these differences would be perceptible.

Surprisingly, liquids had no significant effects on F3 of non-adjacent vowels. 


\begin{tabular}{|c|c|c|c|c|c|}
\hline & he & said & it & ought & ta \\
\hline F3 & & & & & \\
\hline F2 & & & & $\begin{array}{l}\varnothing 1035>/ \mathrm{l} / 1023 \\
\mathrm{t}(249)=2.1, \mathrm{p}=.034 \\
\varnothing 1034>/ \mathrm{r} / 1024 \\
\mathrm{t}(334)=2.2, \mathrm{p}=.032\end{array}$ & \\
\hline F1 & & $\begin{array}{l}/ \mathrm{r} / 486>/ \mathrm{l} / 471 \\
\mathrm{t}(285)=3.4, \mathrm{p}=.0008\end{array}$ & & $\begin{array}{l}\varnothing 576>/ \mathrm{r} / 569 \\
\mathrm{t}(334)=2.0, \mathrm{p}=.046\end{array}$ & $\begin{array}{l}\varnothing 416>/ 1 / 404 \\
\mathrm{t}(249)=3.1, \mathrm{p}=.002\end{array}$ \\
\hline
\end{tabular}

Table 2: paired t-tests on formant values, by Liquid.

4.3 Effects of liquid position, stress The target words fall into 7 groups that differ as to the liquid's position within the syllable, and whether it is stressed. One of the goals of this study is to determine whether these factors affect the range of coarticulation.

Table 3 presents the results of a series of 2-way ANOVAs with independent factors Liquid (3 levels: $\mathrm{r}$, l, neither) and Group (7 levels: stressed simple onset, unstressed simple onset, stressed complex onset, unstressed complex onset, stressed syllabic, unstressed syllabic, stressed coda). Note that any main effects of Group are irrelevant; they may stem from any of the factors not controlled across groups. The question of interest is whether Group and Liquid interact.

No significant interactions between Liquid and Group are found on non-adjacent vowels (they do occur for F1 and F2 on the immediately adjacent word be, not shown here). This suggests that liquids' position and stress are irrelevant to their long-range effects.

\begin{tabular}{|c|c|c|c|c|c|}
\hline & He & said & it & ought & ta \\
\hline F3 & & & & & \\
\hline F2 & & & & $\begin{array}{l}\text { main effect of Group } \\
F(2,6)=6.1, p<.001\end{array}$ & $\begin{array}{l}\text { main effect of Liquid } \\
F(2,6)=3.6, p=.026\end{array}$ \\
\hline F1 & & $\begin{array}{l}\text { main effect of Liquid } \\
F(2,6)=3.5, p=0.031\end{array}$ & & $\begin{array}{l}\text { main effect of Group } \\
F(2,6)=2.1, p=0.048\end{array}$ & $\begin{array}{l}\text { main effect of Liquid } \\
F(2,6)=3.0, p=.049\end{array}$ \\
\hline
\end{tabular}

Table 3: 2-way ANOVAs on formant values, independent factors Liquid (3 levels: $r$, l, neither), and Group (7 levels: stressed onset, etc.).

Some main effects of Liquid do appear on non-adjacent vowels, but they are only marginally significant. Note that the effects of following liquid on the F1 and F2 of ought, which were weak in the paired t-tests, do not appear in the ANOVA. On the other hand, there is a significant effect of Liquid on F2 in ta, which was not found in the paired t-tests ${ }^{3}$.

${ }^{3}$ In the paired-tests on $\mathrm{F} 2$ of $t a, \mathrm{p}=.16$ for $/ \mathrm{r} / \mathrm{vs} / \mathrm{l} /, \mathrm{p}=.10$ for $\varnothing \mathrm{vs} / \mathrm{l} / \mathrm{p}=.10$ for $\varnothing \mathrm{vs} / \mathrm{r} / . \mathrm{F} 2$ was higher before $/ \mathrm{r} /$ than $/ \mathrm{l} /$, as would be expected based on this speaker's pronunciation of $/ \mathrm{r} /$ and $/ \mathrm{l} /$, and higher before $\varnothing$ than either liquid. 
A second series of ANOVAs separated the liquid's stress and position as factors. A 3-way ANOVA was run on each formant of each vowel, with formant value as the dependent variable and Liquid, Position, and Stress as independent variables. Significant results are summarized in Table 4. As before, only main effects and interactions involving Liquid (L) are relevant to the question of long-range liquid coarticulation. We find only one such interaction in a non-adjacent syllable (F2 of $t a$ ). Upon examination, this three-way interaction of Liquid x Stress x Position proved complex and difficult to interpret, and we do not discuss it here.

\begin{tabular}{|l|l|l|l|l|l|}
\hline & he & said & \multicolumn{1}{c|}{ it } & \multicolumn{1}{c|}{ ought } & \multicolumn{1}{c|}{ ta } \\
\hline F3 & & & Stress x Position * & & \\
\hline F2 & & & $\begin{array}{l}\text { Position ** } \\
\text { Position } x \text { Stress } \\
* *\end{array}$ & $\begin{array}{l}\text { Liquid * } \\
\text { Liquid x Stress x Position * }\end{array}$ \\
\hline F1 & & $\begin{array}{l}\text { Liquid * } \\
\text { Position ** }\end{array}$ & Position ** & Liquid * & Liquid * \\
\hline
\end{tabular}

Table 4: 3-way ANOVAs on formant values by Liquid (L), Position (P), Stress (S).

${ }^{*} \mathrm{p}<.05,{ }^{* *} \mathrm{p}<.01,{ }^{* * *} \mathrm{p}<.001$.

In short, there is virtually no evidence that the stress of the target liquid, or its position within the syllable, affect any long-range coarticulation it may have.

\section{Discussion}

5.1 Summary of salient results This study finds only limited evidence for long-range effects of liquid coarticulation in a California speaker. Although some apparent effects of liquids on preceding frame sentence vowels do emerge, they are not statistically very robust, nor highly consistent in nature. Long-range differences are limited to F1 and F2. F1 differences show up in 3 non-adjacent vowels, but don't always distinguish the same triggers (/r/ vs. /l/, /l/ vs neither, or /r/ vs. neither). In one non-adjacent vowel, $\mathrm{F} 2$ values are lower before both liquids compared to non-liquids. This is different from the results of Kochetov \& Neufeld 2013, where only F3 values showed long-range effects. It is also surprising in light of the fact that F3 seems to be the most prominent difference between /r/ and /l/ themselves.

The long-range effects that do occur are not affected by whether the liquid is in a stressed or unstressed syllable, nor whether the liquid is in onset, nucleus or coda position. This may be because our speaker does not reverse the clear/dark distinction in liquids between onset and coda, as some Americans do.

In one analysis, based on t-tests with paired tokens, weak long-range effects seem to occur in stressed ought, with F1 lower before /r/ than a non-liquid, and F2 lower before /r/ or /l/ than a non-liquid. Heid \& Hawkins (2000), Tunley (1999:74), and Kochetov \& Neufeld (2013) all found that stressed syllables did not participate in long-range coarticulation, although coarticulation could spread through these syllables to affect preceding unstressed syllables. Any participation of ought in long-range coarticulation would be surprising. However, our results are too statistically weak to say with confidence that this occurs.

Although one speaker cannot be considered representative of a dialect, our results are consistent with the possibility that long-range liquid coarticulation is weaker in North American English than British English.

5.2 Implications for the dissimilation debate As noted in the introduction, the existence of longrange liquid resonances has been cited as support for the theory that long-distance liquid dissimilation could stem from perceptual errors (Ohala, 1981; Hall, 2007). Under this view, listeners can be unsure whether rhoticity heard on a vowel, for example, is a feature of the vowel itself, or anticipatory coarticulation with an upcoming rhotic. If the listener overcorrects for expected coarticulation, this can cause a word like 


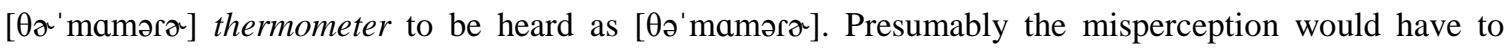
happen often for an alternative pronunciation like [ $\theta$ ə'mamərə] to become acceptable.

The lack of large or robust effects found in this study is a challenge to this theory. Although the presence of $/ \mathrm{r} /$ or $/ \mathrm{l} /$ occasionally significantly affected formants in preceding words, the acoustic effect was very small, and was restricted to F1 and F2. Since arguably the most distinctive acoustic property of /r/ is its low F3 values, it seems implausible that the kind of long-range coarticulation found here could cause listeners to be confused between [ə] and [ə] in a word with a later rhotic. Furthermore, the differences in mean formant value before $/ \mathrm{r} /, / \mathrm{l} /$ and neither were so small in magnitude that we would expect them to be barely noticeable, if at all.

For long-range coarticulation to produce diachronic dissimilation, it would need to trigger perceptual errors on a regular enough basis for the misperceptions to become lexicalized. It seems highly implausible that the weak coarticulation found here could do this.

However, it should be noted that American /r/-dissimilation is a within-word phenomenon, not reported to occur across word boundaries except perhaps in some formulaic phrases (Hempl, 1893). This study, like most others, examined only coarticulation across word boundaries. It is possible that long-range coarticulation might be stronger and / or affect different formants within words, in which case it still might be a cause of dissimilation. This is a topic for future study.

\section{References}

Boersma, Paul and David Weenink. (2016). Praat: doing phonetics by computer [Computer program]. Version 6.0.23, retrieved from http://www.praat.org/

Hall, Nancy. (2007). Perceptual errors or deliberate avoidance? Types of English /r/-dissimilation. In Proceedings of the $37^{\text {th }}$ Annual Meeting of the Berkeley Linguistic Society, 33(1), 133-144.

Hawkins, Sarah, and Andrew Slater. (1994). Spread of CV and v-to-v coarticulation in British English: Implications for the intelligibility of synthetic speech. In ICSLP, 94(1), 57-60.

Heid, Sebastian, and Sarah Hawkins. (2000). An acoustical study of long-range-domain /r/ and /l/ coarticulation. In Proceedings of the $5^{\text {th }}$ seminar on speech production: Models and data, 77-80.

Heinrich, Antje, Yvonne Flory, and Sarah Hawkins. (2010). Influence of English r-resonances on intelligibility of speech in noise for native English and German listeners. Speech Communication, 52(11), 1038-1055.

Hempl, George. (1893). Loss of $r$ in English through dissimilation. Dialect Notes 1.279-81.

Kelly, John and John Local. (1986). Long-domain resonance patterns in English. International conference on speech input/output; techniques and applications (pp. 304-309). London: Institution of Electrical Engineers.

Kewley-Port, Diane, \& Watson, Charles S. (1994). Formant-frequency discrimination for isolated English vowels. The Journal of the Acoustical Society of America, 95(1), 485-496.

Kochetov, Alexei, and Chris Neufeld. (2013). Examining the extent of anticipatory coronal coarticulation: A long-term average spectrum analysis. In Proceedings of Meetings on Acoustics ICA2013, 19(1), 060300. ASA.

Maloney, Brianna, Louise Barbosa, and Nancy Hall. (2016). Long-range liquid coarticulation in American English: a preliminary study. In Proceedings of the National Conference on Undergraduate Research, 2182-2187

Martin, Andrew. (2007). The evolving lexicon (Unpublished doctoral dissertation). UCLA, Los Angeles.

Mondorf, Britta. (2003). Support for more-support. In Günter Rohdenburg \& Britta Mondorf (Eds.), Determinants of grammatical variation in English (pp. 251-304). Berlin, DE: Mouton de Gruyter.

Ohala, John J. (1981). The listener as a source of sound change. Papers from the Parasession on Language and Behavior, (pp. 251-274). Chicago, IL: Chicago Linguistics Society.

Olive, Joseph P., Alice Greenwood, and John Coleman. (1993). Acoustics of American English speech: a dynamic approach. New York, NY: Springer Science \& Business Media.

Rosenfelder, Ingrid, Josef Fruehwald, Keelan Evanini, and Jiahong Yuan. (2011). FAVE (forced alignment and vowel extraction) program suite [Computer program]. Retrieved from http://fave.ling.upenn.edu.

Stanton, Juliet. (2016). Segmental blocking in dissimilation: An argument for co-occurrence constraints. Paper presented at 2016 Annual Meeting on Phonology, University of Southern California, October 2016.

Tunley, Alison. (1999). Coarticulatory influences of liquids on vowels in English (Unpublished doctoral dissertation). University of Cambridge, Cambridge. 
West, Paula. (1999a). Perception of distributed coarticulatory properties of English /l/ and /r/. Journal of Phonetics, 27(4), 405-426.

West, Paula. (1999b). The extent of coarticulation of English liquids: An acoustic and articulatory study. In Proceedings of the International Conference of Phonetic Sciences, 1901-1904. 